\title{
Disconnect between science and end-users as a barrier to climate change adaptation
}

\author{
Anthony S. Kiem*, Emma K. Austin \\ Environmental and Climate Change Research Group, School of Environmental and Life Sciences, \\ Faculty of Science and Information Technology, University of Newcastle, Callaghan, NSW 2308, Australia
}

\begin{abstract}
Much research into climate change impacts and adaptation has been, and continues to be, conducted. However, the well documented themes and recommendations continue to emerge with little evidence of effective climate change adaptation strategies being implemented. This is because while climate change adaptation strategies are not hard to develop, it is difficult to evaluate their effectiveness or, in some cases, even define effectiveness. Compounding this is the fact that implementing strategies that in theory, or in pilot studies, are potentially effective is complicated due to political, economic, legislative and science constraints and the difficulties associated with decision making under uncertainty. Here we focus on Australian rural communities and have found that a major barrier to implementation of effective adaptation strategies is the disconnect between the information that end-users need (or think they need) and the existing outcomes of climate change impacts and adaptation research. While previous research, and anecdotal evidence, qualitatively establishes that a 'gap' does exist, this study represents a preliminary attempt at quantifying the causes and magnitude of the disconnect: a necessary first step in addressing the challenge posed by this barrier to adaptation. The findings are relevant beyond Australia, beyond the agriculture sector, and beyond climate change science, and highlight the need for urgent work aimed at bridging the gap between scientists and decision makers (and other end-users).
\end{abstract}

KEY WORDS: Interdisciplinary studies $\cdot$ Adaptation $\cdot$ Decision making $\cdot$ Agriculture $\cdot$ Terminology

\section{INTRODUCTION}

Effective climate change adaptation strategies are rarely implemented, and in the few instances where they are, it is most often done as part of climate risk management, disaster risk reduction, resource planning or sustainable development initiatives (Adger et al. 2007, Howden et al. 2007). Generally decision makers manage risk holistically; however, climate information is usually derived from reductionist methods (i.e. a complex issue is analysed by its simplest and most basic components) which sometimes leads to distortion (e.g. Sarewitz 2000, Meinke et al. 2006a, Hulme 2011, Lindzen 2012). This difference in approaches is one possible reason for the fundamental disconnect between scientists and end-users (i.e. de- cision makers), meaning that the creation of information relating to climate change impacts, although scientifically sound, sometimes lacks relevance (Meinke et al. 2006a, McNie 2007, Kiem \& Verdon-Kidd 2011). This disconnect often prevents the effective exchange of information between climate scientists (i.e. climate change information producers) and end-users across a range of sectors and contexts (Pielke Jr 2007, Li et al. 2010, Ekstrom et al. 2011, Dilling \& Lemos 2011, Lemos et al. 2012). This disconnect is a particular issue within the agricultural sector and rural communities, as climate change compounds existing vulnerabilities caused by exposure to hydroclimatic extremes, falling commodity prices, rural demographic shifts and a changing farming industry (Kiem et al. 2010, Rickards 2012, Kiem \& Austin 2013). 


\section{POTENTIAL SOURCES OF THE DISCONNECT}

Numerous studies (e.g. Adger et al. 2009, Amundsen et al. 2010, Moser \& Ekstrom 2010, McNeeley 2012, Bierbaum et al. 2013, Biesbroek et al. 2013) have revealed potential causes that contribute to the disconnect between existing science outcomes and end-user needs: some are general barriers preventing the flow of science to decision making and some are specific to climate change adaptation (see Lemos et al. 2012 for a recent review of this field). Some of these barriers or sources of the disconnect are summarised below.

(1) Uncertainty in the meaning, understanding and use of key terminology. Due to the diverse range of disciplines that engage in climate change adaptation research, and due to their differing epistemologies, there is a lack of consensus when defining or understanding key terms (e.g. Miller et al. 2008, Moser \& Ekstrom 2010). Some examples include: the terms resilience and vulnerability, which have very different definitions in the physical and social sciences; confusion between what is weather and what is climate; knowing the difference between a prediction, a forecast, and a projection; knowing the difference between uncertainty, likelihood, risk and vulnerability; knowing the difference between a best estimate scenario, a median scenario from an ensemble of global climate model outputs, and a plausible scenario; knowing the difference between precision and accuracy. This lack of agreement on key terminology and interchangeable or uninformed usage in the scientific community causes confusion amongst both end-users and producers.

(2) Cognitive bias. Epistemologies guide researcher's perspectives on the validity of knowledge (e.g. quantitative versus qualitative), the legitimacy of methods to produce knowledge and, the assumptions associated with concepts and methodologies (e.g. Miller et al. 2008). Add to that the fact that endusers are focussed on solutions rather than research problems and it becomes clear that while interdisciplinary research is required for successful climate change adaptation, there are significant challenges created when researchers (and end-users) with different epistemologies work together.

(3) Scientific publication and peer review. Most journal editors and peer reviewers are academics or full-time research scientists, and as a result peer reviewed literature is biased towards science needs rather than end-user perspectives (i.e. end-users and decision makers have minimal input as to what actually gets published). End-user and policy relevant journal articles require end-users being involved in the peer review process (for an example of the challenges associated with publishing a paper that appeals to non-scientist natural resource managers and also climate scientists and hydrologists refer to discussions at www.hydrol-earth-syst-sci-discuss.net/8/C 5642/2012/hessd-8-C5642-2012.pdf, and the links contained therein, associated with the publication of Gallant et al. 2012). Unfortunately, there is minimal incentive (or time) for non-academics to be involved in the peer review process, just as there is minimal incentive for researchers to publish in low impact factor trade journals or industry magazines (Jacobs et al. 2005). This issue has been repeatedly identified as a major source of the disconnect (e.g. Jacobs et al. 2005; Kiem et al. 2010; Rickards 2012; Kiem \& Austin 2013), since peer reviewed literature, while scientifically sound, is apparently becoming increasingly irrelevant to end-users (as discussed in Point (2), above, relating to credibility and legitimacy). Accessibility is also an issue for end-users or decision makers wanting to read journal articles given that subscriptions to scientific journals can be expensive and usually only available to university affiliates.

(4) Uncertainty in science and how to deal with it. Science is inherently uncertain and always will be. Decisions are regularly made under uncertainty or with only partial knowledge about likely consequences (e.g. investment decisions, career decisions, decisions concerning our health, etc.). However, when it comes to climate science, many are reluctant to consider climate change adaptation until the science is more certain (e.g. Jacobs et al. 2005, Kiem \& Austin 2013). Unfortunately, uncertainty surrounding climate science will not disappear (e.g. Kiem \& Verdon-Kidd 2011) and novel frameworks for climate adaptation decision-making under uncertainty, and research aimed at translating uncertainty into risk, are urgently required. Much can be learned from the extensive body of knowledge relating to assessing and dealing with climate risks (i.e. climate risk in general, as opposed to impacts and risks associated with anthropogenic climate change), much of which pre-dates the emphasis on climate change adaptation (e.g. Hammer et al. 2000, Hayman 2000, Cash et al. 2003, McKeon et al. 2004, Adger et al. 2005, Meinke et al. 2006b, 2009, Hayman et al. 2007).

(5) Competition between social, political, environmental and economic drivers. There are suggestions that the disconnect is not so much between the science and the decision makers, rather it is that the decision has to be socially, politically, economically and environmentally acceptable for it to be implemented (e.g. Adger et al. 2005, Füssel 2007, Moser \& Ekstrom 2012). 
Even in a perfect world where scientists provide useful information to end-users and end-users subsequently make robust climate change adaptation decisions based on that science, if people do not like the decision, there will always be difficulty in getting that decision implemented (e.g. when a desalinisation plant or reservoir is proposed, when water trading or allocation schemes are introduced, when sea-level inundation or flood management policies are changed, etc.).

Finally, it is important to note that issues associated with the utility of scientific information are not unique to climate change adaptation, and that lessons previously learnt about conceptualisation and measuring knowledge use are useful. The literature on knowledge utilisation, while mostly focused on education and health policy arenas, contains some pertinent information on possible reasons for the disconnect between science and end-users (e.g. Weiss 1980, Dunn 1983, Rich 1991). Further, from the broader perspective of finding solutions and moving forward, the social sciences can help address many issues related to knowledge transfer and use, which (as mentioned above) typically are social and political in nature.

\section{METHODS}

While anecdotal evidence (e.g. from the surveys, interviews and workshops conducted as part of studies such as Kiem et al. 2010, Rickards 2012 and Kiem \& Austin 2013) and the previous research mentioned (e.g. Lemos et al. 2012 and the references therein) qualitatively establish that a disconnect does exist between climate science and end-users, minimal information is available as to its specific causes, particularly for Australia and especially for rural communities. Here we quantify potential causes of this disconnect through an online survey designed to test the hypothesis that there is a difference between whether producers of climate science and end-users or decision makers think available information is useful (with particular emphasis on end-users with connection to Australian rural communities). Further information on the online survey is provided in Section 3.1 and it is the analysis of the survey responses which forms the focus of this paper. The online survey is intended to preliminarily ground-truth the anecdotal evidence and other information coming out of the literature, interviews and workshops. It is emphasised that the workshop and interview information is used only to help clarify and support the conclusions emerging from the survey results rather than as a basis for the conclusions.

\subsection{The online survey}

A copy of the survey questions are included in Fig. S1 in the Supplement (www.int-res.com/articles/ suppl/c058p029_supp.pdf). The online survey was designed and distributed as follows: (1) Ethics approval was obtained from the University of Newcastle's Human Research Ethics Committee (HREC) due to the involvement of human participants. (2) The online survey tool Survey Monkey was used to host the online survey. This software was selected for the range of features available, in particular the text analysis function. (3) Survey questions (both open ended and multiple choice) were developed to take into consideration discussions with various stakeholders, and insights gained from the literature review and previous studies (e.g. Cash \& Buizer 2005, Kiem et al. 2010). Survey questions were designed to facilitate a quantitative analysis of the disconnect, which to date has only been investigated qualitatively. All respondents completed the same questions. (4) The survey was open to everyone but was initially disseminated via email lists and other networks and organizations that the researchers are associated with (see Table S1 in the Supplement at www.int-res.com/articles/suppl/c058p029_supp.pdf). Respondents were also encouraged to distribute the survey to their own contacts and networks. Hard copies of the survey were also provided upon request. This included a group of rural community members in South Australia and Victoria. The distribution of hard copy surveys attempted to engage rural community members who did not have access to the internet or are not computer literate.

Both qualitative and quantitative analyses were performed on the data collected from the survey responses. Survey responses were categorised into 8 participant groups based on whether respondents identified as being (1) a producer of climate information or not, (2) an end-user of climate information or not, (3) a member of, or having an effect on, rural communities or not, and (4) someone who did or did not use climate information in their decision making (Table 1).

\subsubsection{Qualitative analysis}

The online survey software used (i.e. Survey Monkey) enabled analysis of 'free text' responses via word clouds. The use of word clouds is an increasingly utilised method for synthesizing research by multidisciplinary working groups (Rubin \& Fornari 
Table 1. Survey respondents were classified into 8 participant groupings. These groups indicate whether the respondent identifies as a climate information producer or end-user and their connection to rural communities

I produce information about future climate change 1 impacts that could potentially be used by people in rural communities

2 I produce information about future climate change impacts that is NOT relevant to rural communities

3 I use information about future climate change impacts to make policy decisions that affect rural communities I use information about future climate change impacts 4 to make policy decisions; however, these decisions DO NOT affect rural communities

5 I use information about future climate change impacts to make business/operational decisions, and I AM a rural community member

I use information about future climate change impacts to make business/operational decisions, and I AM NOT a rural community member

I DO NOT use information about future climate 7 change impacts to make business/operational decisions, and I AM a rural community member

I DO NOT use information about future climate change impacts to make business/operational decisions, and I AM NOT a rural community member

2011). Word cloud representations are used to allow researchers using different methodologies and approaches to identify common ground and hence points of intersection within their research. The font size of individual words is indicative of the number of times they were used in the responses. Therefore, larger words were used more frequently than smaller words, and this is assumed to give some indication as to what is and is not important. It must be noted that word clouds have several limitations including the fact that context is unable to be determined from a word cloud and hence it is not possible to tell whether a word or phrase is being used from a positive or negative perspective. Limitations also include the potential for inaccuracies as a result of spelling mistakes and the use of several derivatives of the same word, or the case where certain words may be repeated often but not have the same weight as a key word that is used less frequently. Nevertheless, in this study, word clouds are a useful tool for quickly analysing the large amounts of text that emerged from the survey in order to get an initial insight into the issues that may or may not be important. Note also that in this study, due to limited sample sizes for some groups, word clouds were, applied to the results as a whole (i.e. all 8 groups' responses considered together), meaning that the word cloud results are skewed towards the more populated groups (see Fig. 1 for the percentage of survey respondents within each group).

\subsubsection{Quantitative analysis}

In Question 13 of the survey, respondents were asked to give their opinion (via a Likert scale of none, low, fair, high or excellent) on 9 characteristics of the available information about future climate change impacts. The characteristics assessed were:

(1) Availability: the climate information required by the end-user is available.

(2) Awareness: respondents are aware of where to find the climate information they need.

(3) Understanding: respondents understand the climate information that they access or are able to access.

(4) Exists: respondents' opinion on what climate information actually exists.

(5) Format: the format of the climate information meets respondents' needs. Format relates to presentation (e.g. is information given in graphs or tables, is it online or in hard copy, is it a 100 page report or a 2 page brochure?)

(6) Detail: the level of detail meets the needs of respondents. For example, detail relates to the spatial and temporal scale of information such as forecasts and the variables included such as averages as opposed to totals or extremes.

(7) Relevance: how relevant is the climate information to the respondents' needs?

(8) Credibility: refers to the scientific rigour of the evidence and arguments presented in the climate information.

(9) Legitimacy: refers to whether the production of information is based on accepted standards and logical reasoning, particularly with respect to how the information represents and satisfies the needs of all stakeholders (Cash \& Buizer 2005).

Chi-square and ANOVA tests were then used to determine if there was any statistically significant relationship between the participant group that people identified with and their responses to Question 13 , with the null hypothesis $\left(H_{0}\right)$ being that there is no association (i.e. for a given characteristic all participant groups have a similar opinion). Chi-square and ANOVA testing produces a p-value for each set of variables, which indicates the probability that the $H_{0}$ is true; in this study p-values $<0.05$ were used to indicate that there is statistically significant support for the rejection of $H_{0}$. 
Chi-square and ANOVA testing was again applied to the responses to test if respondents from a given participant group rated characteristics similarly or differently. Whereas previous tests compared one characteristic for all 8 participant groups, these tests compared all characteristics for one participant group, $H_{0}$ again being that there is no association (i.e. for a given participant group their opinion is similar for all characteristics of climate change information).

In addition, 2-tailed Student's $t$-tests were performed to determine if any of the 8 participant groups had a significantly different distribution of response than that associated with all other responses. This was done for each of the 9 characteristics, with $H_{0}$ being that the distribution of responses associated with an individual participant group is equivalent to the distribution of responses associated with all other participant groups. That is, for each of the 9 characteristics, the $H_{0}$ is that the responses from a certain participant group were not different to the responses from all other participants.

\section{RESULTS}

\subsection{Summary of online survey participants}

A total of 383 individuals (48\% female and $52 \%$ male) responded to the online survey. All but 3 respondents (2 from the United Kingdom and 1 from America) were from Australia with $66 \%$ from New South Wales, $14 \%$ from Victoria, 10\% from Queensland, 4\% from South Australia, 3\% from Western Australia, $2 \%$ from Tasmania and 1\% from the Northern Territory. The survey respondents were spread across most age brackets: $1 \%$ aged $<20 \mathrm{yr}$, $12 \%$ aged $20-29,18 \%$ aged $30-39,24 \%$ aged $40-49$, $26 \%$ aged $50-59,15 \%$ aged $60-69$, and $4 \%$ aged $\geq 70$, with the oldest respondent born in 1926 (85 years old) and the youngest respondent born in 1992 (19 years old). The majority of respondents (88\%) had completed tertiary education and a further $8 \%$ had completed a Trade Certificate/Diploma or equivalent. Due to insufficient sample sizes, analysis was not conducted on the influence of age or education on endusers' utilisation and perception of information about future climate change impacts, but it is possible that results may be sensitive to this. Further investigation into this issue is recommended, as people with ages and educational backgrounds not well represented may have different opinions to those obtained here.

The perceived usefulness of available climate change information is indicative of the magnitude of the disconnect, as the usefulness determines the capacity of information to be translated into action (e.g. Verdon-Kidd et al. 2012). If information is not useful, it cannot inform decisions and facilitate the management of climate related risk. When asked whether they thought existing information about climate science or climate change impacts was useful (Question 8), 70\% of respondents agreed that it is, but $26 \%$ said that it is not and $4 \%$ said they would not know as they do not use it. The fact that more than a quarter of respondents did not believe climate change information is useful provides clear evidence of the magnitude of the disconnect. The potential reasons behind this result, and whether or not producers perceive climate change information as more useful than end-users, are examined by analysing responses stratified by participant groupings and investigating exactly which aspects of climate change information each group has problems with. Refer to Table 1 for an explanation of the participant groupings and Fig. 1 for the distribution of participants within each group. Due to restrictions enforced by the ethics clearance required for the online survey, the amount of personal information gained about the survey participants was limited to the demographic information discussed above and self-classification into 1 of the 8 participant groups. In hindsight it is clear that it would also be useful (and relevant) to know more about the role of climate information endusers (or potential end-users) - e.g. What exactly is their role within business or government? Are they responsible for decisions at a national, state, regional or local level? Which climate related decisions are they responsible for? What exactly is their role within or link to rural communities or some other sector? Subsequent research for a recently completed National Climate Change Adaptation Research Facility (NCCARF) project (Verdon-Kidd et al. 2012) has focussed on these questions and the fact that endusers' expectations and needs regarding information about future climate change impacts will vary depending on their role (see Section 5 for further discussion and recommendations on this issue).

\subsection{Analysis of free text responses: what people really think}

There were 10 questions in the survey that required free text responses, and the responses to 2 of these questions are illustrated in Fig. 2a,c using word clouds.

Fig. 2a, supported by Fig. 2b, suggests that the preferred sources of information about future climate 


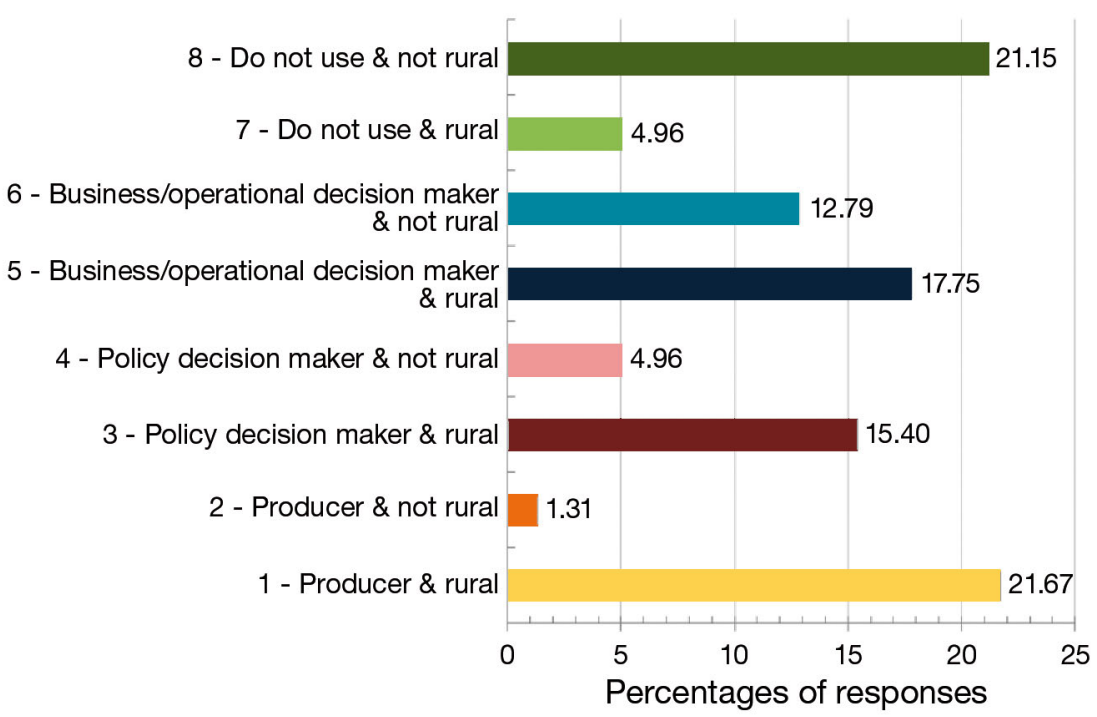

Fig. 1. Percentage of survey respondents within each of the 8 participant groups. Total responses $=383$

change impacts are websites, email, workshops/ meetings, journal articles and local media (e.g. radio, newspapers). Despite the preference for using technology as a way to access information, there is still a substantial number of people who prefer information to be passed on personally (i.e. via workshops/meetings or face-to-face contact). This is consistent with previous experiences where there was consensus that informal forums such as 'Fireshed gatherings' (i.e. informal community gatherings that happen in the shed belonging to the local fire fighting service or the town hall or similar) were crucial in providing the opportunity for rural community members to discuss business and operational related issues while also socialising (Kiem et al. 2010). These types of interactions are considered to be beneficial not only in terms of information exchange, but also for the mental health and wellbeing of members of rural communities who can often be disengaged and isolated (Kiem \& Austin 2013). It is also important to note that the survey results relating to preferred sources of information are likely biased towards websites and email, as data was gathered via an online survey. Therefore, it is possible that an entire group of potential respondents has failed to be engaged in this (and other) research due to its online nature. The issue of internet access (or lack of) in rural Australia is a theme that is repeated throughout the literature, and in interactions with participants during similar research (e.g. MCVP 2012, Rickards 2012). It is clear that the lack of internet and phone coverage in some

\section{a \\ ABC Radio National Academic Research $\mathrm{Clim}$ ate $\mathrm{contacts}_{\mathrm{CS}} \mathrm{RO}$ \\ Documentaries Environmental Federal Govt Future

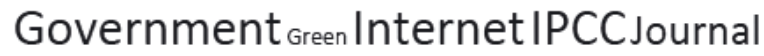 Articles Journal Publications LGSA Magazines Media Net NewS Peer Reviewed Journals Relevant Science Journals Sources studies Treterion}

\section{Action Adaptation case studies Clear Climate} Change Day to Day Decision Making Education Extreme

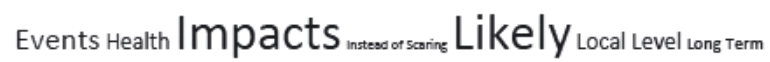
Models Politicians Presented question Regional Reliable Risk Sea Level Rise succes stories $_{\text {Temperature Think Truth }}$ Variability

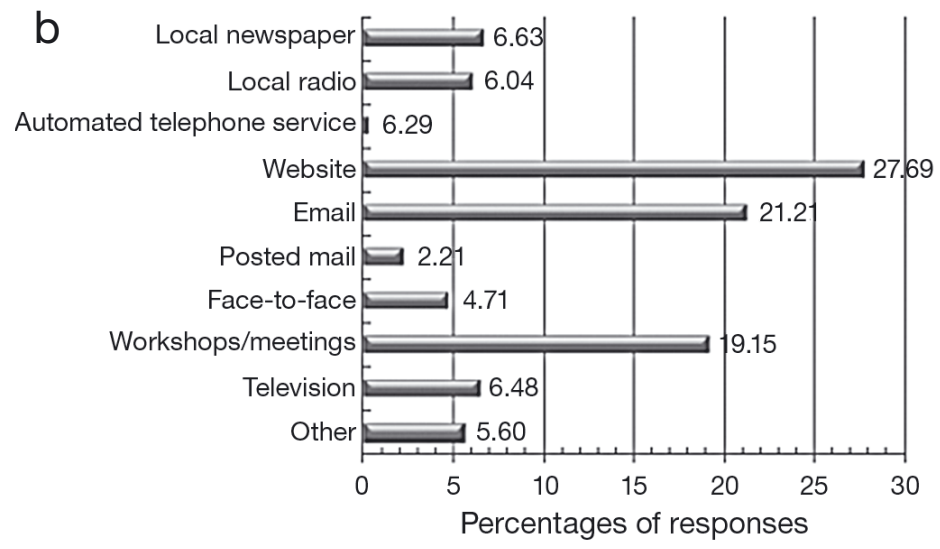

Fig. 2. (a) Most used 26 words and phrases in responses to Question 9 which asked where people sourced information about future climate change impacts. (b) Distribution of responses for Question 20 which asked which was the best way to receive information about climate change impacts. (c) Most used 27 words and phrases in responses to Question 14 which asked respondents what information about future climate change impacts is required for successful climate change adaptation 
rural areas is considered to be a major barrier to accessing climate change information. This significant issue is exemplified by the survey response from one rural community member from South Australia:

'The major weakness we have to deal with every day is slow unreliable internet access and phone coverage to take advantage of new information. For example, we would love to install soil moisture probes that can send us data via mobile phone. However we have no coverage, so are unable to use this technology. Sometimes it is not the weakness of information, but the delivery and sharing of it. Rural areas seem to suffer the most from poor technology and lack of coverage and services, hindering the uptake of the most recent available knowledge.'

This highlights that rural community members with poor access to internet or communication networks are not usually well represented in research results, do not have access to online products, surveys or information sheets, and are possibly too remote to attend workshops or conferences. Further investigation is needed to establish the proportion of people affected by this issue, how best to engage them, and whether or not these people are adequately represented by people from rural communities who can access the internet, complete online surveys, and attend workshops. Future research must also evaluate the implementation of Australia's National Broadband Network (www.nbn.gov.au/) and determine if this group has been successfully engaged (i.e. just because people have internet access does not mean they are computer literate or want to engage in computer based research; some rural and remote areas will not have the same level of coverage as other areas, etc.).

Fig. 2c provides insight into what end-user needs are in terms of climate information. The need for regional information on the impacts of climate variability and change is emphasised, and is a theme throughout many free text responses to a variety of questions, as is the need for improved information on extremes, climate related risks, and what is likely or reliable.

\subsection{Quantifying the disconnect: rating of information on climate change impacts and adaptation}

Participants were asked to give their opinion (via a Likert scale of none, low, fair, high or excellent) on 9 characteristics of information on future climate change impacts (refer to Section 3.1.2 for details). Chi-square and ANOVA testing (Table 2) revealed

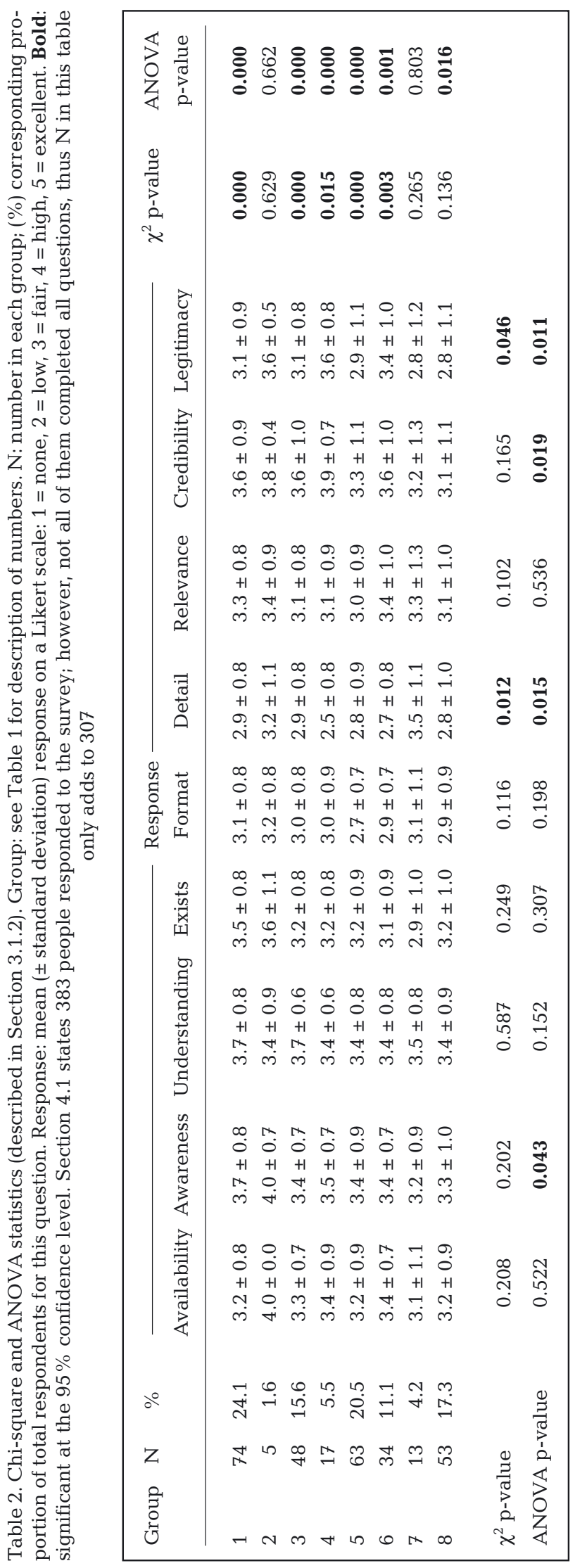


that respondents from some participant groups had an opinion that was statistically significantly different to respondents from other participant groups for at least 2 of the characteristics considered (i.e. 2 characteristics emerged as significant, irrespective of whether a chi-square or ANOVA test was used). These 2 characteristics were detail and legitimacy. This is supported by Fig. 3, which demonstrates that legitimacy and detail (and also format) have higher percentages of respondents rating these variables as fair or below.

Chi-square tests were also performed to determine if respondents from a given participant group rated characteristics similarly or differently (Table 2). Whereas previous tests compared one characteristic for all 8 participant groups, these tests compared all characteristics for one participant group. Table 2 shows that participant Groups 1, 3, 4, 5 and 6 have statistically significant associations with the responses for the 9 characteristics irrespective of whether a chi-square or ANOVA test was used. This also supports patterns illustrated in Fig. 3 which demonstrates that in particular participant Groups 3, 4, 5 and 6 have issues with format and detail while Groups 5, 7, and 8 have issues with legitimacy. Note that Group 1 also has issues with legitimacy, which is initially counter intuitive (since Group 1 are 'producers' of the climate change impacts information). However, it is suggested that what this reveals is that producers of scientific information can be well aware of complexities and uncertainties, and worried that paring information down to provide clear and comprehensible messages sometimes underemphasises (or neglects) important provisos and disclaimers.

Despite the low sample size for Group 2, it is also worth noting that Fig. 3 suggests markedly differing

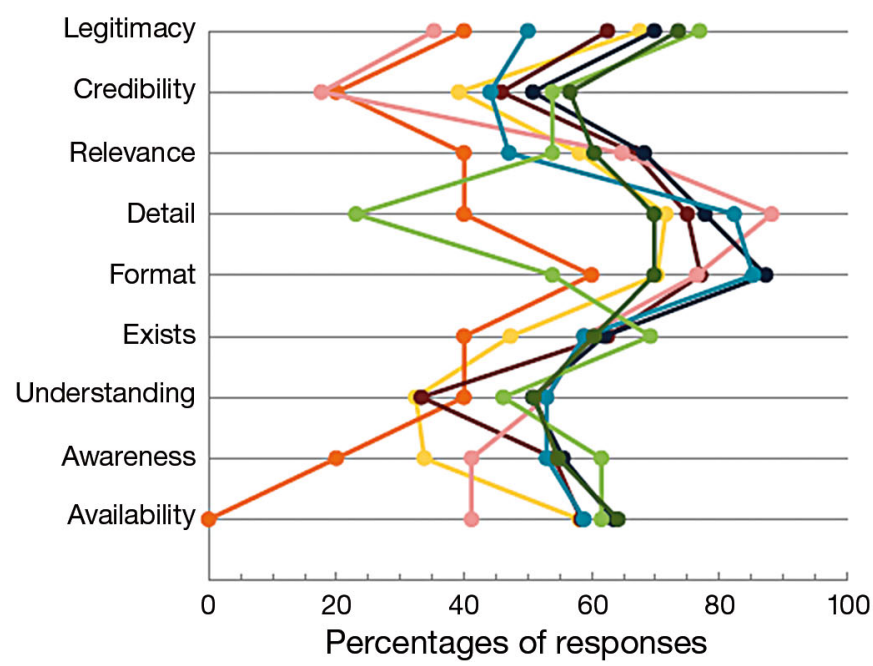

opinions of producers (Groups 1 and 2) on the availability of climate change information depending on whether they consider that the information they produce could be used to inform the rural sector. Of the producers that do not think climate change information is relevant to rural communities (Group 2), none rate the availability of climate change information end-users need as fair or below (i.e. all in this group think the availability of climate change information is satisfactory), compared with almost $60 \%$ of producers who acknowledge links with rural communities (Group 1) rating the available information as only fair or below.

The comparison of response distributions using $t$ tests allowed further quantification of the magnitude of the disconnect and also identified some significant results that were not captured by the chi-square and ANOVA tests. Participant Group 2 again returned a significantly higher response distribution than the remaining respondents ( $p=0.049$ ) for availability, suggesting they are more satisfied with availability than other respondents. Similarly, participant Group 1 produced a significantly higher distribution $(\mathrm{p}=0.002)$ than other respondents for awareness. These results demonstrate that, as would be expected, producers (i.e. Groups 1 and 2) are more aware of, and have a different perspective on, the availability of climate information than do end-users of the information. Importantly, Group 8 produced a lower response $(\mathrm{p}=$ 0.077) for awareness than the remaining groups, suggesting that one reason people in this category do not use climate change information may be because they are unaware of it. Other results that are informative as to the potential causes of the disconnect include:

(1) Group 1 (producers of climate change impact information that is relevant for rural communities)

\footnotetext{
-1 - Producer \& rural

$\rightarrow 2$ - Producer \& not rural

$\rightarrow 3$ - Policy decision maker \& rural

$\rightarrow 4$ - Policy decision maker \& not rural

$\rightarrow 5$ - Business/operational decision maker \& rural

$\rightarrow 6$ - Business/operational decision maker \& not rural

$\approx 7$ - Do not use \& rural

$\rightarrow 8$ - Do not use \& not rural
}

Fig. 3. Percentage of respondents that selected fair or below for the 9 characteristics of information on future climate change impacts (see Section 3.1.2 for details) 
returning significantly higher ratings for knowing what climate change information exists $(p=0.018)$ and understanding what they can or could access $(\mathrm{p}=0.013)$;

(2) Group 5 (rural community members that use climate change information to make business decisions) returning significantly lower ratings for format $(\mathrm{p}=0.030)$;

(3) Group 4 (non-rural policy makers) having significantly higher rankings for credibility $(p=0.040)$ while Group 8 (non-rural and non-users of climate information) had significantly lower rankings ( $p=$ 0.016). This indicates that decision makers will only use climate change information if they think it is credible. Also important to note is that the policy decisions made by Group 4 do not affect rural communities, indicating that policy decision makers whose decisions do affect rural communities have a lower opinion of the credibility of available information;

(4) Group 4 (as with credibility and as suggested by the chi-square tests) ranked legitimacy significantly higher than other respondents $(p=0.028)$, and Group 8 ranked legitimacy significantly lower than other respondents $(p=0.020)$, indicating that whether or not people use climate change information also depends on whether they think it is legitimate.

\section{DISCUSSION: OVERCOMING THE DIFFERENCES BETWEEN PRODUCERS AND END-USERS OF CLIMATE INFORMATION}

The type of scientific information scientists and/or researchers are interested in often differs from what end-users and decision-makers need. It is clear from the results presented here, and in previous studies (e.g. Meinke et al. 2006b, Kiem et al. 2010, Li et al. 2010, Ekstrom et al. 2011, Kiem \& Verdon-Kidd 2011, Gallant et al. 2012, Lemos et al. 2012, Rickards 2012, Kiem \& Austin 2013), that better synthesis, translation and packaging of climate science could be useful for end-users, and also would increase scientists' awareness of the needs of end-users, and the ability to work towards addressing these needs. A recently completed NCCARF project (Verdon-Kidd et al. 2012) considers this and investigates the idea of a 'knowledge broker' (also known as 'boundary workers' or 'boundary organisations') as one way to bridge the gap between producers and end-users (e.g. Guston et al. 2000, Cash et al. 2003, Lemos et al. 2012). Fig. 4 illustrates the outcome of preliminary discussions focussed on where the 'knowledge broker' fits and its role.
It is suggested that the 'knowledge broker' role, which is undoubtedly onerous, would be to know and communicate to producers who the end-users are and what their roles are, to understand and communicate to producers what is required by end-users, to know and communicate to end-users what is available from climate science (including the strengths and limitations of what is available), to synthesise scientific literature, to ensure consistency in termino$\operatorname{logy}$, to provide a co-ordinated mechanism for accessing climate datasets, to translate uncertainty into an assessment of risk (if possible) and to facilitate education and discussions between end-users and science providers. This would also include strengthening interactions between producers/providers/researchers and end-users, and addressing weaknesses or gaps, by building teams that contain an appropriate mixture of research and communication/outreach skills. There is evidence that end-users do appreciate interacting with knowledge-providing experts who understand and address their needs, but they are wary if that person (or organisation) is thought to be filtering (or possibly modifying) the science (e.g. Hart et al. 2012, Lemos et al. 2012, Moser \& Ekstrom 2012, Kiem \& Austin 2013); hence, the 'knowledge broker' needs to be more than just a middleman. These studies also reveal that there is not so much a need for more climate science outputs as a need for improved packaging of information such that it is consistent, legitimate, credible and useful for end-users and decision makers. As mentioned in the Introduction and Section 2, lessons can be learnt from older studies on knowledge utilisation in fields such as education and health policy (e.g. Weiss 1980, Dunn 1983, Rich 1991).

Useful lessons can also be obtained from recent studies (e.g. Tribbia \& Moser 2008, Hart et al. 2012, Moser \& Ekstrom 2012) that reveal interesting insights into the timing of the demand (and end-user or decision-maker perception of the need) for a 'knowledge broker'. Hart et al. (2012) found, also from a survey, that there were surprisingly few people claiming that there was a need for more scientific information (meaning for the Californian coastal communities Hart et al. (2012) studied, lack of scientific information was not really a barrier to their climate change adaptation processes). Moser \& Ekstrom (2012) (an update of Tribbia \& Moser 2008) also found that surprisingly few people in their study on managers of coastal communities (interview and observationbased) talked about lack of science as a barrier to climate change adaptation. The conclusion reached was that the communities studied (Tribbia \& Moser 


\section{SCIENCE AND RESEARCH OUTPUTS}

(Climate science, hydrology, adaptation, sea-level change, decision making, uncertainty and risk quantification etc)

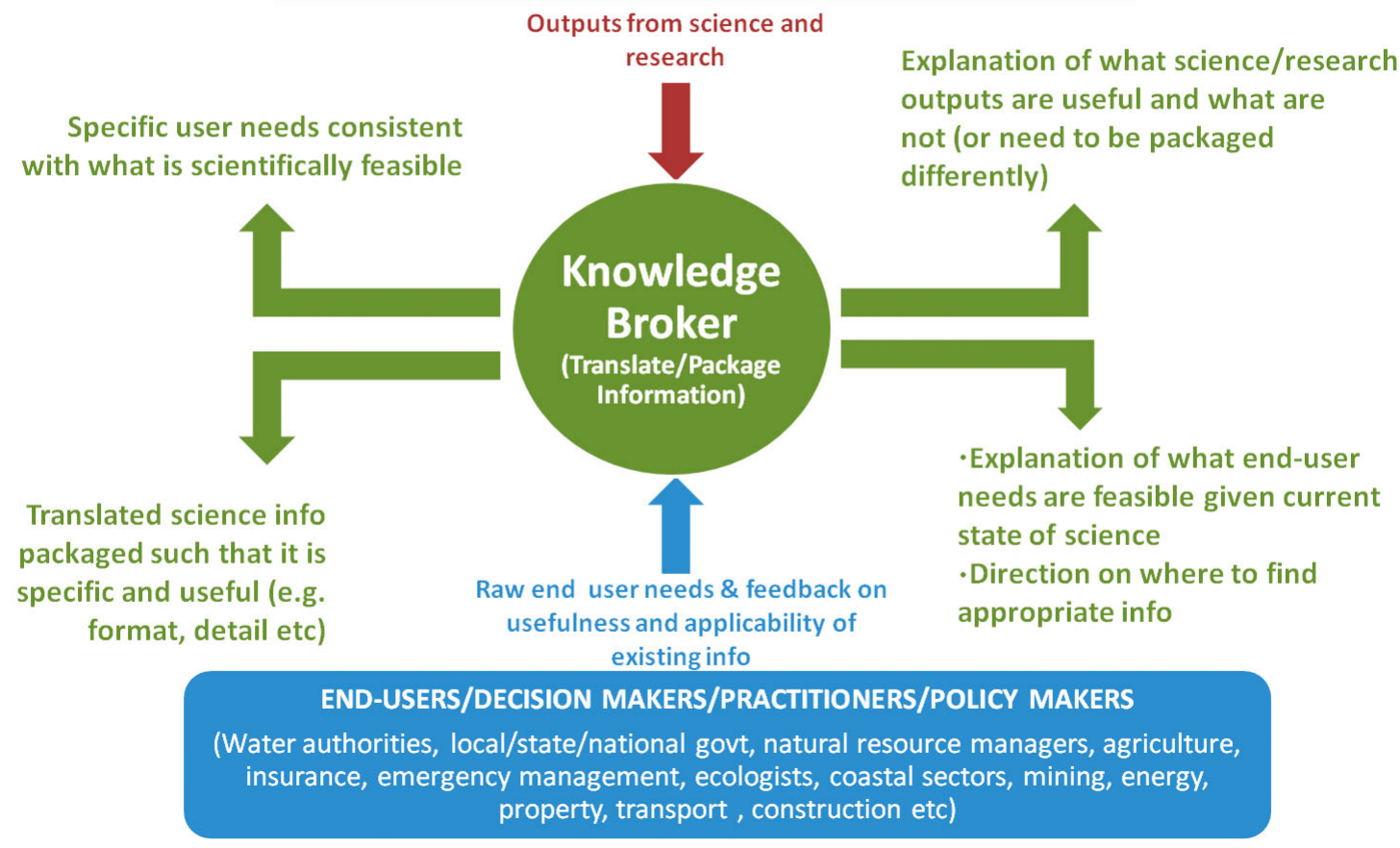

Fig. 4. Schematic outlining the role of the 'knowledge broker' (from A. S. Kiem et al. unpubl.)

2008, Hart et al. 2012, Moser \& Ekstrom 2012) do not 'need' science information because they are not far enough along in the climate change adaptation process to see the need for more science information or to be able to use it if it were available. Verdon-Kidd et al. (2012) also found that there is not so much a need for more climate science outputs; however, those that are farther along the climate change adaptation process (e.g. agricultural communities and water resource managers in Australia) do need improved packaging of information such that it is consistent, legitimate, credible and useful for end-users and decision makers, and given limited capacity and capabilities within many existing decision-making organisations, a 'knowledge broker' could be put to good use.

In addition to being an onerous role, another difficulty facing the successful co-production of knowledge required to address the disconnect and increase the usefulness of climate science information, is the way climate science is currently funded. As addressed in the Introduction and Section 2, the needs and drivers of researchers and end-users are different. Science and research funding is mostly allocated based on researcher track record (i.e. journal publications) and/or novel science. Hence, if capacity is to be increased in the 'knowledge broker' space (e.g. providing information that helps with the management of a farm), significant changes to the way research and researchers are judged and funded is required (e.g. weighted less on the number of journal publications and h-index and more towards whether end-users' questions are being answered and practical needs are being met). If the disconnect (or differences) are to be addressed, then end-users need more of a voice in determining the design of the information products; this type of participatory research would be an important role of the 'knowledge broker', as would the provision and packaging of science information.

\section{CONCLUSIONS}

This study investigated one of the many barriers to climate change adaptation: the disconnect between available climate information and the needs of rural community end-users. Qualitative and anecdotal evidence suggests the disconnect exists; however, its characteristics, magnitude, and causes have not been quantified. 
Key insights emerging are:

(1) Large quantities of climate change information exist and many producers and end-users consider this information to be useful. However, a considerable proportion of potential end-users of climate information (and some producers of climate science information) do not believe available climate information is useful, do not know where to find it, do not understand it or do not use the information in their decision making;

(2) Lack of legitimacy and detail, and inappropriate format, appear to be the major causes of the disconnect, and the extent of dissatisfaction is dependent on the group the survey respondents came from;

(3) Producers and end-users rate characteristics of information about climate change impacts very differently;

(4) End-users view climate information differently as a consequence of the type of decisions they make based on the information (i.e. policy or business/ operational). Importantly, both producers and end-users also view the information very differently as a factor of their connection (or not) to rural communities.

Based on these insights it is recommended that future work focuses on testing the following hypotheses: (1) there is a difference in the way end-users view available climate information depending on the type of decisions they are using the information for; (2) the high level of uncertainty involved in climate science and future climate scenarios is prohibitive for end-users; (3) the levels of relevance, credibility and legitimacy of climate information are connected in a relationship whereby efforts made to enhance one may degrade another (Cash \& Buizer 2005). Further investigation is also required to determine whether there is any association between the comprehension of (and opinion regarding) climate change information and age, level of education or any other typology.

A limitation of this study (and many others) was that it relied on people completing an online survey. Large numbers of rural community end-users do not have access to available climate information due to a lack of internet or mobile phone coverage in many areas of Australia. In addition, rural community endusers who do have internet and mobile phone coverage, may not be in a position to utilise available information due to a lack of computer and technological literacy. If this issue is found to be significant, then the exclusion of rural community members from research as a result of their remote locations and increasing reliance by researchers on the internet for surveys and reporting needs to be addressed. Poten- tially, entire groups of end-users have been omitted from research programs and are therefore not considered in the research outcomes. Future research must evaluate the implementation of Australia's National Broadband Network (www.nbn.gov.au/) and determine if this group has been successfully engaged (i.e. just because people have internet access does not mean they are computer literate or want to engage in computer based research; some rural and remote areas will not have the same level of coverage as other areas etc.). Another important limitation of the survey is that it is possible that the producers (i.e. researchers) who are actively involved with end-users did not complete the survey (e.g. they are too busy). Therefore, in follow up work it will be useful to determine what proportion of producers or researchers are actively involved in producing material designed for end-users, and are interacting with these end-users. Also of interest would be the proportion of producers or researchers in Australia who are from organisations that see a substantial part of their role as informing end-users. Answers to these questions are required in order to better understand, and to address, the disconnect between climate science and end-users or decision makers.

There are significant uncertainties, limits and barriers that impede effective adaptation to climate change. Useful information is vital to assist end-users in their adaptation decision making. Currently, a disconnect exists that prevents documented priorities and recommendations from being implemented. This disconnect is very evident in rural communities, where the impacts of climate change exacerbate existing vulnerabilities caused by exposure to hydroclimatic extremes, falling commodity prices, rural demographic shifts and a changing farming industry. It is crucial this disconnect be overcome in order to make effective adaptation to climate change more achievable. This study presents some potential ways to do this.

\section{LITERATURE CITED}

Adger WN, Arnell NW, Tompkins EL (2005) Successful adaptation to climate change across scales. Glob Environ Change 15:77-86

Adger WN, Agrawala S, Mirza MMQ, Conde C and others (2007) Assessment of adaptation practices, options, constraints and capacity. In: Parry ML, Canziani OF, Palutikof JP, van der Linden PJ, Hanson CE (eds) Climate change 2007: impacts, adaptation and vulnerability. Contribution of Working Group II to the Fourth Assessment Report of the Intergovernmental Panel on Climate Change. Cambridge University Press, Cambridge

Adger WN, Dessai S, Goulden M, Hulme M and others 
(2009) Are there social limits to adaptation to climate change? Clim Change 93:335-354

> Amundsen H, Berglund F, Westskog H (2010) Overcoming barriers to climate change adaptation: a question of multilevel governance? Environ Plann C Gov Policy 28: 276-289

> Bierbaum R, Smith JB, Lee A, Blair M and others (2013) A comprehensive review of climate adaptation in the United States: more than before, but less than needed. Mitig Adapt Strategies Glob Change 18:361-406

Biesbroek GR, Klostermann JEM, Termeer CJAM, Kabat P (2013) On the nature of barriers to climate change adaptation. Reg Environ Change 13:1119-1129

Cash DW, Buizer J (2005) Knowledge-action systems for seasonal-to-interannual climate forecasting. National Academies Press, Washington, DC

$>$ Cash DW, Clark WC, Alcock F, Dickson NM and others (2003) Knowledge systems for sustainable development. PNAS 100:8086-8091

> Dilling L, Lemos MC (2011) Creating usable science: opportunities and constraints for climate knowledge use and their implications for science policy. Glob Environ Change 21:680-689

Dunn WN (1983) Measuring knowledge use. Sci Commun 5: 120-133

Ekstrom JA, Moser SC, Torn M (2011) Barriers to climate change adaptation: a diagnostic framework. California Energy Commission www.energy.ca.gov/2011publica tions/CEC-500-2011-004/CEC-500-2011-004.pdf

Füssel HM (2007) Adaptation planning for climate change: concepts, assessment approaches, and key lessons. Sustain Sci 2:265-275

Gallant AJE, Kiem AS, Verdon-Kidd DC, Stone RC, Karoly DJ (2012) Understanding hydroclimate processes in the Murray-Darling Basin for natural resources management. Hydrol Earth Syst Sci 16:2049-2068

Guston DH, Clark WC, Keating T, Cash DW, Moser SC, Miller C, Powers C (2000) Report of the Workshop on Boundary Organizations in Environmental Policy and Science, 9-10 December 1999. Bloustein School of Planning and Public Policy, Rutgers University, New Brunswick, NJ; Belfer Center for Science and International Affairs (BCSIA) Discussion Paper 2000-32. Environmental and Occupational Health Sciences Institute at Rutgers University and UMDNJ, Piscataway, NJ; Global Environmental Assessment Project, Environment and Natural Resources Program, Kennedy School of Government, Harvard University, Cambridge, MA, available at http://belfercenter.hks.harvard.edu/publication/2760/ report_of_the_workshop_on_boundary_organizations_in _environmental_policy_and_science.html

Hammer GL, Nicholls N, Mitchell C (eds) (2000) Applications of seasonal climate forecasting in agricultural and natural ecosystems: the Australian experience, Kluwer, Dordrecht

Hart JA, Grifman PM, Moser SC, Abeles A, Myers MR, Schlosser SC, Ekstrom JA (2012) Rising to the challenge: results of the 2011 Coastal California Adaptation Needs Assessment. USCSG-TR-01-2012, available at www.usc. edu/org/seagrant/research/climateadaptsurvey/Survey Report_FINAL_OnlinePDF.pdf

Hayman PT (2000) Communicating probabilities to farmers: pie charts and chocolate wheels. In: Petheram R (ed) A manual of tools for participatory r\&d in dryland cropping areas. Rural Industries Research and Development, Can- berra, p 133-136, available at https://rirdc.infoservices. com.au/items/00-132

Hayman PT, Crean J, Parton KA, Mullen JM (2007) How do seasonal climate forecasts compare to other innovations that farmers are encouraged to adopt? Aust J Agric Res 58:975-984

Howden SM, Soussana JF, Tubiello FN, Chhetri N, Dunlop M, Meinke H (2007) Adapting agriculture to climate change. Proc Natl Acad Sci USA 104:19691-19696

> Hulme M (2011) Reducing the future to climate: a story of climate determinism and reductionism. Osiris 26: 245-266

> Jacobs K, Garfin G, Lenart M (2005) More than just talk: connecting science and decision making. Environ Sci Policy Sustain Dev 47(9):6-21

Kiem AS, Austin EK (2013) Drought and the future of rural communities: opportunities and challenges for climate change adaptation in regional Victoria, Australia. Glob Environ Change 25:1307-1316

Kiem AS, Verdon-Kidd DC (2011) Steps towards 'useful' hydroclimatic scenarios for water resource management in the Murray-Darling Basin. Water Resour Res 47: W00G06, doi:10.1029/2010WR009803

Kiem AS, Askew LE, Sherval M, Verdon-Kidd DC and others (2010) Drought and the future of rural communities: drought impacts and adaptation in regional Victoria, Australia. National Climate Change Adaptation Research Facility (NCCARF), Gold Coast, available at www.nccarf.edu.au/publications/drought-and-futurerural-communities

Lemos MC, Kirchhoff CJ, Ramprasad V (2012) Narrowing the climate information usability gap. Nature Clim Change 2:789-794

Li GM, Dovers S, Sutton P, Guillaume J and others (2010) IACCIUS: synthesis report on integrated assessment of climate change impacts on urban settlements. Fenner School of Environment and Society, The Australian National University, Canberra

Lindzen RS (2012) Climate physics, feedbacks, and reductionism (and when does reductionism go too far?). Eur Phys J Plus 127:52

McKeon G, Hall W, Henry B, Stone G, Watson I (2004) Pasture degradation and recovery in Australia's rangelands: learning from history. Queensland Department of Natural Resources, Mines, and Energy, Brisbane

McNeeley S (2012) Examining barriers and opportunities for sustainable adaptation to climate change in Interior Alaska. Clim Change 111:835-857

McNie EC (2007) Reconciling the supply of scientific information with user demands: an analysis of the problem and review of the literature. Environ Sci Policy 10:17-38

MCVP (Managing Climate Variability Program) (2012) Climate Champion Program: Australia. MCVP, available at www.managingclimate.gov.au/climate-champion-program/

Meinke H, Howden M, Nelson R (2006a) Integrated assessments of climate variability and change for Australian agriculture: connecting the islands of knowledge. 3rd Bienniel Meet Int Environ Model Softw Soc, 9-12 July, Burlington, VT

> Meinke H, Nelson R, Kokic P, Stone R, Selvaraju R, Baethgen W (2006b) Actionable climate knowledge: from analysis to synthesis. Clim Res 33:101-110

> Meinke H, Howden M, Struik PC, Nelson R, Rodriguez D, Chapman SC (2009) Adaptation science for agriculture and natural resource management: urgency and theoret- 
ical basis. Curr Opinion Environ Sustain 1:69-76

Miller TR, Baird TD, Littlefield CM, Kofinas G, Chapin FS, Redman CL (2008) Epistemological pluralism: reorganising interdisciplinary research. Ecol Soc 13(2):46

Moser SC, Ekstrom JA (2010) A framework to diagnose barriers to climate change adaptation. Proc Natl Acad Sci USA 107:22026-22031

Moser SC, Ekstrom JA (2012) Identifying and overcoming barriers to climate change adaptation in San Francisco Bay: results from case studies. California Energy Commission, CEC-500-2012-034, available at www.energy.ca. gov/2012publications/CEC-500-2012-034/CEC-500-2012 -034.pdf

Pielke RA Jr (2007) The honest broker: making sense of science in policy and politics. Cambridge University Press, Cambridge

Rich RF (1991) Knowledge creation, diffusion, and utilization - perspectives of the founding editor of knowledge. Sci Commun 12:319-337

Rickards L (2012) Critical breaking point: the effects of climate variability, change and other pressures on farm households. Rep Birchip Cropping Group and Sustain-

Editorial responsibility: Bryson Bates,

Wembley, Australia able Agriculture Initiative Platform Australia, available at www.bcg.org.au/cb_pages/news/CriticalBreakingPoint Report.php

Rubin KH, Fornari D (2011) Multidisciplinary collaborations in Mid-Ocean Ridge research. Eos Trans AGU 92(17): $141-142$

Sarewitz D (2000) Science and environmental policy: an excess of objectivity. In: Frodemen R, Baker VR (eds) Earth matters: the earth sciences, philosophy, and the claims of community. Prentice Hall, Upper Sadle River, NJ

Tribbia J, Moser SC (2008) More than information: what coastal managers need to prepare for climate change. Environ Sci Policy 11:315-328

Verdon-Kidd DC, Kiem AS, Austin EK (2012) Decision making under uncertainty: bridging the gap between end user needs and climate science capability. Tech Rep for National Climate Change Adaptation Research Facility (NCCARF), available at www.nccarf.edu.au/publications/ decision-making-under-uncertainty

Weiss CH (1980) Knowledge creep and decision accretion. Sci Commun 1:381-404

Submitted: March 5, 2013; Accepted: July 26, 2013

Proofs received from author(s): October 30, 2013 